\title{
Retrieval of MetOp-A/IASI CO profiles and validation with MOZAIC data
}

\author{
E. De Wachter ${ }^{1}$, B. Barret ${ }^{1}$, E. Le Flochmoën ${ }^{1}$, E. Pavelin ${ }^{2}$, M. Matricardi ${ }^{3}$, C. Clerbaux ${ }^{4,5}$, J. Hadji-Lazaro $^{4}$, \\ M. George ${ }^{4}$, D. Hurtmans ${ }^{5}$, P.-F. Coheur ${ }^{5}$, P. Nedelec ${ }^{1}$, and J. P. Cammas ${ }^{1}$ \\ ${ }^{1}$ Laboratoire d'Aérologie-OMP, Université de Toulouse - CNRS/INSU, UMR5560, Toulouse, France \\ ${ }^{2}$ Met Office, Exeter, UK \\ ${ }^{3}$ ECMWF, Reading, UK \\ ${ }^{4}$ UPMC Univ. Paris 06; Université Versailles St-Quentin, CNRS/INSU - UMR8190, LATMOS-IPSL, Paris, France \\ ${ }^{5}$ Spectroscopie de l'Atmosphère, Chimie Quantique et Photophysique, Université Libre de Bruxelles, Brussels, Belgium \\ Correspondence to: E. De Wachter (wace@ aero.obs-mip.fr)
}

Received: 30 March 2012 - Published in Atmos. Meas. Tech. Discuss.: 4 May 2012

Revised: 18 October 2012 - Accepted: 2 November 2012 - Published: 26 November 2012

\begin{abstract}
The IASI (Infrared Atmospheric Sounding Interferometer) nadir-looking thermal infrared sounder onboard MetOp-A enables the monitoring of atmospheric constituents on a global scale. This paper presents a quality assessment of IASI CO profiles retrieved by the two different retrieval algorithms SOFRID and FORLI, by an intercomparison with airborne in-situ CO profiles from the MOZAIC program for the 2008-2009 period. Lower (surface-480 hPa) and upper tropospheric partial column $(480-225 \mathrm{hPa}) \mathrm{com}-$ parisons as well as profile comparisons are made. The retrieval errors of the IASI products are less than $21 \%$ in the lower troposphere and less than $10 \%$ in the upper troposphere. A statistical analysis shows similar correlation coefficients for the two retrieval algorithms and smoothed MOZAIC of $r \sim 0.8$ and $r \sim 0.7$ in the lower and upper troposphere respectively. Comparison with smoothed MOZAIC data of the temporal variation of the $\mathrm{CO}$ profiles at the airports of Frankfurt and Windhoek demonstrates that the IASI products are able to capture the seasonal variability at these sites. At Frankfurt SOFRID (respectively FORLI) is positively biased by $10.5 \%(13.0 \%)$ compared to smoothed MOZAIC in the upper (lower) troposphere, and the limited sensitivity of the IASI instrument to the boundary layer when thermal contrast is low is identified. At Windhoek, the impact of the vegetation fires in Southern Africa from July to November is captured by both SOFRID and FORLI, with an
\end{abstract}

overestimation of the $\mathrm{CO}$ background values (fire maxima) by SOFRID (FORLI) by $12.8 \%$ (10\%). Profile comparisons at Frankfurt and Windhoek show that the largest discrepancies are found between the two IASI products and MOZAIC for the nighttime retrievals.

\section{Introduction}

Carbon monoxide $(\mathrm{CO})$ is primarily produced at the surface by biomass burning and fossil fuel combustion. In the atmosphere, oxidation of methane $\left(\mathrm{CH}_{4}\right)$ and non-methane hydrocarbons (NMHC), like isoprene, accounts for nearly half of the global CO production (Brenninkmeijer and Novelli, 2003). Sources of secondary importance include emission by vegetation and oceans. The removal of $\mathrm{CO}$ is largely (for as much as $90 \%$ ) determined by the reaction with the hydroxyl $(\mathrm{OH})$ radical. The remaining $10 \%$ is removed by soils (Brenninkmeijer and Novelli, 2003).

Although not considered a greenhouse gas, $\mathrm{CO}$ has a strong indirect effect on the radiation balance of the atmosphere. Through its reaction with $\mathrm{OH}, \mathrm{CO}$ largely determines the oxidizing capacity of the atmosphere, thereby having a strong impact on the lifetimes of long-lived trace gases (Bergamaschi et al., 2000; Shindell et al., 2009). Furthermore, being involved in the production and destruction of 
ozone $\left(\mathrm{O}_{3}\right), \mathrm{O}_{3}-\mathrm{CO}$ correlation studies can provide important insight into the photochemical origin of air masses (Parrish et al., 1993; Chin et al., 1994; Voulgarakis et al., 2011). In addition, having a lifetime in the troposphere of 1-2 months, $\mathrm{CO}$ is an excellent tracer to study the long-range transport of pollution (Logan et al., 1981; Forster et al., 2001).

Thermal infrared (TIR) nadir sounders can provide information about the vertical distribution of tropospheric trace gases with a high spatial resolution. IASI, the Infrared Atmospheric Sounding Interferometer, onboard MetOp-A, is dedicated to long-term global-scale monitoring of a series of key atmospheric species, with unprecedented spatial sampling and coverage (Clerbaux et al., 2009). Laboratoire d'Aérologie (LA) and LATMOS/Université Libre de Bruxelles (ULB) deliver profiles of atmospheric CO based on two different retrieval algorithms: the SOftware for a Fast Retrieval of IASI Data (SOFRID) and the Fast Optimal Retrievals on Layers for IASI (FORLI). This paper provides a comparison of the $\mathrm{CO}$ products obtained by the two algorithms with high precision airborne in-situ $\mathrm{CO}$ observations from the Measurements of OZone, water vapour, carbon monoxide and nitrogen oxides by Airbus In-service airCraft (MOZAIC) program (Marenco et al., 1998). As the FORLI CO products will be operationally distributed in 2013 through the EUMETCast system (under the O3MSAF umbrella), this paper is an important step to evaluate the quality of the $\mathrm{CO}$ profile data before widespread distribution.

The SOFRID algorithm was developed at LA for the fast retrieval of $\mathrm{O}_{3}$ and $\mathrm{CO}$ profiles on a global scale from IASI spectra. Barret et al. (2011) showed that tropospheric SOFRID $\mathrm{O}_{3}$ profiles can be retrieved with almost two independent pieces of information with errors smaller than $20 \%$ : the tropospheric ozone column (surface-225 hPa) and the upper tropospheric-lower stratospheric (UTLS) column (225$70 \mathrm{hPa}$ ). Given the great value of coexistent observations of $\mathrm{O}_{3}$ and $\mathrm{CO}$ on a global scale, SOFRID has been expanded to allow the retrieval of $\mathrm{CO}$ profiles. Our goal is to describe the SOFRID CO retrieval in detail and assess the quality of the retrieved profiles through a comparison with MOZAIC aircraft data.

The FORLI algorithm (Hurtmans et al., 2012) provides daily retrievals of $\mathrm{CO}, \mathrm{O}_{3}$ and $\mathrm{HNO}_{3}$. The FORLI CO product comprises $\mathrm{CO}$ total columns, partial columns, profiles, quality flags and the corresponding averaging kernel vector or matrix. It has undergone a series of quality assessments. George et al. (2009) evaluated global distributions of FORLI CO total columns with the nadir-looking TIR instruments MOPITT, AIRS and TES. A qualitative analysis of the FORLI-retrieved CO profiles was made by Turquety et al. (2009) by analysing the performance of the CO retrievals during extreme fire events. Pommier et al. (2010) compared total columns, $0-5 \mathrm{~km}$ partial columns and profiles with collocated aircraft observations in the Arctic during the spring and summer 2008 POLARCAT campaigns. This study complements the previous works by validation of FORLI CO profiles against the MOZAIC 2008-2009 dataset.

The paper is structured as follows: in Sect. 2 the two algorithms developed to retrieve $\mathrm{CO}$ profiles from IASI radiances are introduced. Section 3 presents the MOZAIC reference dataset used in the validation study, and in Sect. 4 the validation methodology and results are discussed. The conclusion is given in Sect. 5 .

\section{Retrieval from MetOp-A/IASI radiances}

\subsection{IASI}

IASI is one of the 12 instruments onboard MetOp-A, the first of a series of successive polar-orbiting satellites. Launched in October 2006, IASI is a Fourier transform spectrometer (FTS), designed to measure the infrared (IR) spectrum emitted by the Earth and the atmosphere, from 645 to $2760 \mathrm{~cm}^{-1}$, with a spectral resolution of $0.5 \mathrm{~cm}^{-1}$ after apodization. As compared to other TIR sounders in orbit, IASI offers a large and continuous spectral coverage of the IR region at a medium spectral resolution (Clerbaux et al., 2009). It provides global Earth coverage twice a day, with an overpass time at $\sim$ 09:30 and $\sim 21: 30$ LT (local time) and a nadir spatial resolution of $50 \mathrm{~km} \times 50 \mathrm{~km}$, composed of $2 \times 2$ circular pixels, each corresponding to a $12 \mathrm{~km}$ diameter footprint on the ground at nadir (Clerbaux et al., 2009).

IASI's objectives are the delivery of highly accurate meteorological products to help improve operational weather predictions, as well as the monitoring of reactive gases on a global scale.

\subsection{SOFRID}

The SOFRID algorithm aims at a fast retrieval of global $\mathrm{O}_{3}$ and CO from MetOp/IASI radiances. It is based on the RTTOV fast radiative transfer model coupled to a $1 \mathrm{D}-\mathrm{Var}$ retrieval scheme. The retrieval of SOFRID $\mathrm{O}_{3}$ profiles is described in detail in Barret et al. (2011), and a validation study with ozonesondes is given by Dufour et al. (2012). For this validation study SOFRID v2.0 was used.

The UKMO 1D-Var algorithm (Pavelin et al., 2008) is a retrieval code for nadir-viewing passive sounding satellites, developed at UK Met Office within the context of the EUMETSAT Satellite Application Facility for Numerical Weather Prediction (NWP SAF). It is based on the optimal estimation method (OEM) described by Rodgers (2000). In the OEM an optimal solution is found given the measurement, a simulation of the observed radiance, the a priori information and associated errors. Hence, an accurate radiative transfer model and a representative set of a priori assumptions and their uncertainties need to be provided.

The radiative transfer calculations are performed with the RTTOV-9.3 fast radiative transfer model developed for the meteorological community within the NWP-SAF. The 

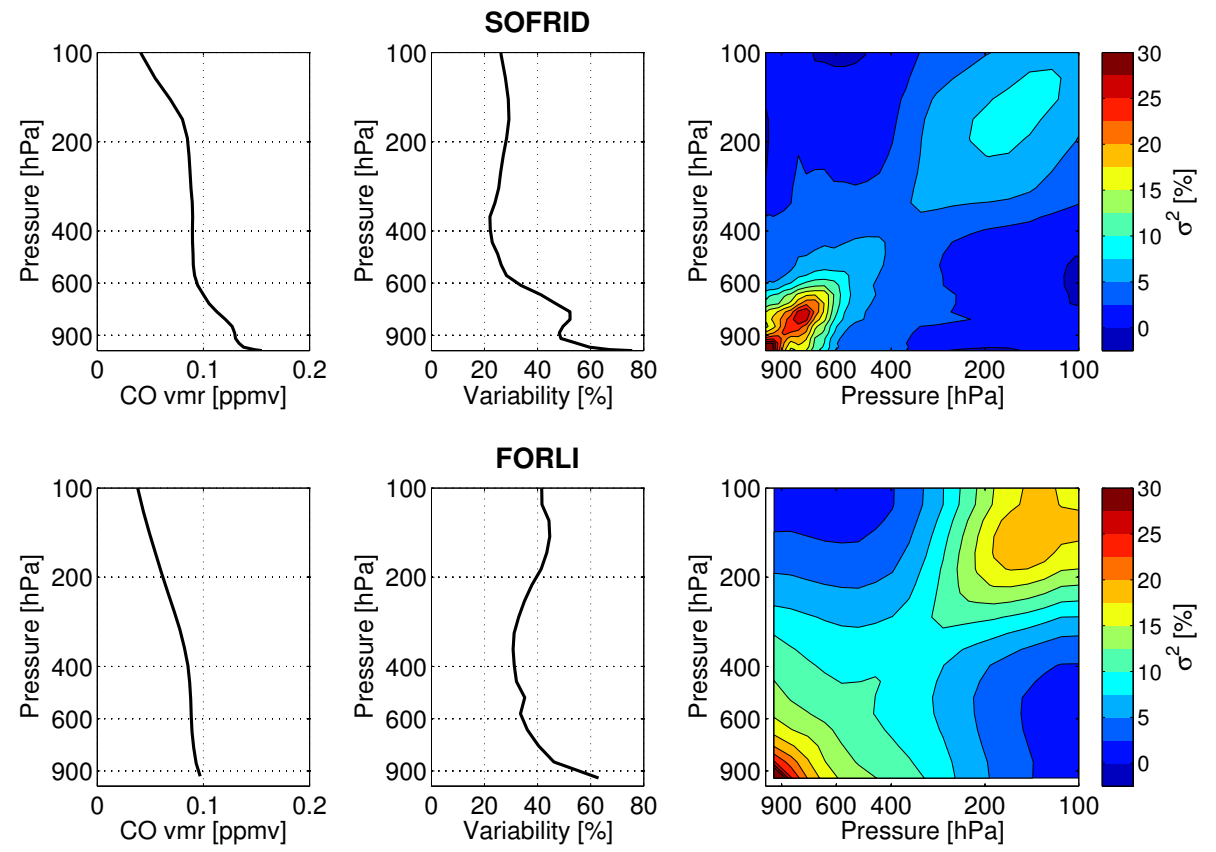

Fig. 1. For SOFRID (top panels) and FORLI (bottom panels): the a priori profile (left panel), the a priori variability (middle panel) and the a priori covariance matrix (right panel).

RTTOV algorithm is described in detail in Saunders et al. (1999) and Matricardi et al. (2004). The overall accuracy of RTTOV has been addressed using IASI data in Matricardi (2009). The RTTOV software is available free of charge on request from NWP-SAF at http://research.metoffice.gov.uk/ research/interproj/nwpsaf/rtm/rtm/rttov9.html. General documentation about RTTOV is provided at this website, and detailed information about the IASI radiative transfer in RTTOV is provided in Technical Memoranda (cited in the above-mentioned publications) at the ECMWF website (http: //www.ecmwf.int/publications/library/do/references/list/14).

RTTOV is a regression model where optical depths are parameterised by a set of predefined profile-dependent predictors, which are functions of temperature, pressure, absorber amount and viewing angle (Matricardi et al., 2004). The RTTOV regression coefficients are derived from accurate lineby-line calculations performed with the line-by-line radiative transfer model (Clough et al., 2005) using molecular data from the HITRAN 2004 spectroscopic database (Rothman et al., 2005). The land emissivity is calculated with the RTTOV UWiremis IR land surface emissivity module (Borbas and Ruston, 2010). The surface pressure, temperature and humidity profiles are taken from the operational MetOp-A Level 2 (L2) IASI product (Schlüssel et al., 2005). Surface temperature, skin temperature and wind speed are provided by the European Centre for Medium-range Weather Forecasts (ECMWF).

SOFRID CO retrievals are calculated from radiances in the $2143-2181 \mathrm{~cm}^{-1}$ spectral window and are retrieved on 43 fixed pressure levels from the surface up to $0.1 \mathrm{hPa}$. The covariance of the measurement error is characterized by a 5-band matrix (i.e. a pentadiagonal matrix, which is representative for apodised observations) with a radiometric noise set to $1.41 \times 10^{-8} \mathrm{~W}\left(\mathrm{~cm}^{2} \mathrm{srcm}^{-1}\right)^{-1}$. This value is almost a factor 10 higher than the estimated radiometric noise in this spectral region (Clerbaux et al., 2009), to roughly take uncertainties in fixed parameters (such as temperature profile, spectroscopic parameters and surface emissivity) into account. In the following we will refer to this term as the augmented noise (see Sect. 2.4).

The a priori information was built from a 2-yr dataset of MOZAIC aircraft CO profiles, complemented by Aura/MLS profiles at altitudes higher than the aircraft altitude. A fixed global a priori profile $\boldsymbol{x}_{\mathrm{a}}$ is used for all the retrievals, shown in the top left panel of Fig. 1. Its variability is given in the top middle panel, calculated from the square root of the diagonal of the a priori covariance matrix, given in the upper right panel. We see the highest variability in the lowermost layers of the atmosphere, due to localised fossil fuel and biomass burning, with an a priori variability of $\sim 70 \%$ at the surface decreasing to $50 \%$ near $800 \mathrm{hPa}(\sim 1.5 \mathrm{~km})$ and to $20-30 \%$ for pressures lower than $600 \mathrm{hPa}(\sim 4 \mathrm{~km})$.

In this spectral range, $\mathrm{H}_{2} \mathrm{O}$ is the main interfering gas, while $\mathrm{N}_{2} \mathrm{O}$ contributes to the signal at higher wavenumbers. To account for their contributions, both profiles are retrieved simultaneously with $\mathrm{CO}$, as well as surface temperature.

A cloud filtering is applied according to Clerbaux et al. (2009), based on the AVHRR-derived fractional cloud cover from the IASI EUMETSAT L2 products. Only pixels with a cloud fraction between 0 and $25 \%$ are processed. In addition, 
the brightness temperatures at the $11 \mu \mathrm{m}$ (BT11) and $12 \mu \mathrm{m}$ (BT12) IASI channels are compared to the ECWMF skin temperature. If either the difference between BT12 and the ECMWF skin temperature is larger than $10 \mathrm{~K}$ or if BT11 and BT12 are differing more than $\pm 10 \mathrm{~K}$, the pixel is considered as contaminated and eliminated.

The data will be available to the user in HDF data format with the associated total error and instructions on how to calculate the averaging kernels and separate error contributions.

\subsection{FORLI}

The FORLI algorithm has been developed at the Universite Libre de Bruxelles (ULB). It uses pre-calculated lookup tables of absorbance cross sections at various pressures and temperatures instead of the more time-consuming line-bybine calculations, and the optimal estimation for the inverse scheme (Hurtmans et al., 2012). CO profiles are calculated on 19 fixed layers from the surface up to the top of the atmosphere (set to $60 \mathrm{~km}$ ), corresponding to 18 equidistant layers of $1 \mathrm{~km}$ from 0 to $18 \mathrm{~km}$, and a top layer between 18 and $60 \mathrm{~km}$.

FORLI CO profiles are retrieved from radiances in the spectral range $2143-2181 \mathrm{~cm}^{-1}$ (same interval as SOFRID). A diagonal measurement error covariance matrix was chosen, with an average measurement noise corresponding to $1.8 \times 10^{-9} \mathrm{~W}\left(\mathrm{~cm}^{2} \mathrm{srcm}^{-1}\right)^{-1}$, the estimated radiometric noise in this spectral region (Clerbaux et al., 2009). The operational MetOp-A L2 temperature and humidity profiles are used for the radiative transfer calculations. To take into account the wavenumber dependency of the surface emissivity, a climatology built from several years of IASI data (Zhou et al., 2011) is used. In the few cases that there are missing values in the Zhou et al. (2011) climatology, the MODIS/TERRA climatology (Wan, 2008) is used instead.

The a priori information was constructed from aircraft profiles from the MOZAIC program, complemented by ACEFTS (Clerbaux et al., 2005) profiles at the highest altitudes (upper troposphere and above), as well as distributions from the LMDz-INCA (Hauglustaine et al., 2004) global chemistry transport model. The bottom panels of Fig. 1 display the a priori profile, its associated variability and covariance matrix. Compared to SOFRID we see smaller volume mixing ratios (vmrs) near the surface for the a priori profile, and a steeper descending profile in the upper troposphere. FORLI presents larger a priori variability in the upper troposphere $(\sim 35 \%)$ and in the UTLS $(\sim 45 \%)$. Surface temperature, $\mathrm{CO}_{2}$ and $\mathrm{N}_{2} \mathrm{O}$ total columns, and $\mathrm{H}_{2} \mathrm{O}$ profile are retrieved in addition to the $\mathrm{CO}$ profile.

For profiles in the Arctic, Pommier et al. (2010) found differences between FORLI CO and smoothed in situ profiles lower than $17 \%$ in spring, and stated that FORLI overestimates the $\mathrm{CO}$ concentrations compared to the in situ data in summer where differences can reach up to $20 \%$ below $8 \mathrm{~km}$ for polluted cases. George et al. (2009) found total column discrepancies of about $7 \%$ between IASI and other satellite instruments measuring $\mathrm{CO}$ (for the $\mathrm{NH}$ and equatorial region), going up to $17 \%$ when high $\mathrm{CO}$ concentrations are found, e.g. during fire events.

The FORLI CO products are publicly available via the Ether (http://ether.ipsl.jussieu.fr/) database. The data are updated every day with a delay of one month and include the twice daily distributions of $\mathrm{CO}$ total columns since October 2007 along with averaging kernels, associated errors, and quality flags.

For the comparison with MOZAIC data, only the more reliable pixels were taken into account using the quality flags (super quality flag equal to 0 ). For more information see http://ether.ipsl.jussieu.fr/ether/pubipsl/iasi_CO_uk.jsp.

\subsection{Error characterization}

In this study, two error sources contributing to the total retrieval error are considered: the smoothing error, which accounts for the low vertical resolution of the retrievals, and the measurement error. An additional source of error propagating into the total retrieval error is due to uncertainties in forward model parameters. SOFRID uses a conservative value for the radiometric noise to include these uncertainties (the augmented noise; see Sect. 2.2). The error sources from fixed model parameters are currently not explicitly taken into account in FORLI (Hurtmans et al., 2012). Nevertheless, a detailed error analysis of $\mathrm{CO}$ retrievals from similar nadir viewing FTIR spectrometers Aura/TES and ADEOS/IMG was done by Worden et al. (2004) and Barret et al. (2005) respectively. In addition, an error characterization of $\mathrm{CO}$ retrievals from another optimal estimation $\mathrm{CO}$ retrieval scheme of the IASI instrument is given by Illingworth et al. (2011). The different studies come to the same conclusion that the dominant source of error at all altitudes is the smoothing error. Worden et al. (2004) also stated that the measurement error is larger than systematic errors that are due to uncertainties of surface and atmospheric temperature and retrieved and non-retrieved interfering species. We therefore assume that the dominant source of error for IASI CO retrievals is the smoothing error followed by the measurement error. Other error sources contribute to the total error:

- The instrumental and calibration error are considered in the augmented noise term of the SOFRID retrieval.

- The skin temperature is strongly correlated to the surface temperature. For both products the surface temperature is retrieved simultaneously with the $\mathrm{CO}$ profiles and does not provide a significant contribution to the total error (Worden et al., 2004; Barret et al., 2005).

- Worden et al. (2004) showed that spectroscopic uncertainties in the $4.7 \mu \mathrm{m} \mathrm{CO}$ band were small enough to ignore. 
- In the CO retrieval window, the surface emissivity is almost constant with variations lower than 0.01. As both parameters are strongly correlated, retrieving the surface temperature is similar to retrieving the surface emissivity and therefore biases in surface emissivity are corrected. Furthermore differences between FORLI and SOFRID emissivities at both sites are within 0.01. This small difference between 2 databases is a proxy for the uncertainty on the emissivity and shows that this uncertainty could not impact CO retrievals more than $1 \%$. We can therefore assume that emissivity errors will have only a negligible impact upon $\mathrm{CO}$ retrievals. However, it should be stated that, although for most parts of the world the surface emissivity is not an important error source, George et al. (2009) reported studies showing that emissivity of sandy desert regions provides problems for IR retrievals. Given this issue is still unresolved, it has been a reason for generally excluding IR retrieval results over the Sahara and Arabia.

- The ECMWF surface pressure has a typical accuracy of $2-3 \mathrm{hPa}$ (O'Dell et al., 2012), which is about $0.2-$ $0.3 \%$ at sea level. Even increased by interpolation to the IASI pixel, surface pressure errors are therefore negligible compared to the smoothing error.

- Retrieval tests (not shown here) with the wind speed used to compute the sea emissivity or with a constant sea emissivity have shown a negligible impact on the retrieval.

\section{MOZAIC}

The MOZAIC program provides routine measurements of reactive gases on long distance commercial aircraft (Marenco et al., 1998). Since 1994, five airliners have been equipped with $\mathrm{O}_{3}$ and relative humidity instruments, and a $\mathrm{CO}$ analyser was successfully added in December 2001. One aircraft carries an additional instrument to measure total odd nitrogen $\left(\mathrm{NO}_{\mathrm{y}}\right)$ since 2001 (Volz-Thomas et al., 2005). With a measurement precision of $\pm 5 \mathrm{ppbv}$ for a $30 \mathrm{~s}$ integration time, the $\mathrm{CO}$ analyser has a horizontal resolution of about $7 \mathrm{~km}$ and a vertical resolution of about $300 \mathrm{~m}$ during ascents and descents (Nedelec et al., 2003). The MOZAIC data are freely accessible for scientific use at http://www.iagos.org. Since 2009 , the MOZAIC program has been expanded, implementing other commercial in-service aircraft observation programs such as CARIBIC (http://www.caribic-atmospheric. com) into the IAGOS Research Infrastructure (In-service Aircraft for a Global Observing System). In the following however, for simplicity, we will continue to refer to the MOZAIC data.

For the validation of IASI CO, all MOZAIC observations taken at take-off and landing in 2008-2009 were taken into account. The results of the statistical analysis are given in
Sect. 4.3. For most of the 30 airports sampled by MOZAIC in 2008-2009, the number of coincidences with IASI data comprised between 5 and 60 and was insufficient to sample seasonal variations. The two airports Frankfurt, Germany $\left(50.1^{\circ} \mathrm{N}, 8.7^{\circ} \mathrm{E}\right)$, and Windhoek, Namibia $\left(22.6^{\circ} \mathrm{S}, 17.1^{\circ} \mathrm{E}\right)$, are sampled with a high frequency during the 2008-2009 period, and give us the opportunity to study the seasonal cycle at these geographical locations. Therefore a comparative study of the temporal behaviour of the IASI data and the MOZAIC data recorded during take-off and landing at these two airports is investigated in Sect. 4.4.

\section{Validation}

\subsection{Methodology and information content}

Pixels were selected within $\pm 1^{\circ}$ in latitude and longitude from the MOZAIC coordinates. The quality assessment is based on the comparison of partial columns, and a distinction is made between daytime and nighttime IASI retrievals. The averaging kernel matrix $\mathbf{A}$ is an important by-product of the retrieval, which characterizes the sensitivity of the retrieved profile to the true profile. The rows of $\mathbf{A}$ are called the averaging kernels and are peaked functions. For each retrieval level, the width of the averaging kernels corresponds to the altitude range contributing to the retrieved value and therefore gives an indication of the height resolution. The DFS (Degrees of Freedom for Signal) is calculated from the trace of $\mathbf{A}$ and quantifies the number of independent pieces of information on the vertical for each measurement. Calculation of the DFS, for all coincidences with MOZAIC data, gives values that vary between 1.4 and 2.3 for SOFRID and between 1.1 and 2.1 for FORLI. This shows that nearly 2 independent pieces of information can be deduced from the retrieved SOFRID and FORLI CO profiles in the best cases.

Daytime and nighttime averaging kernels of SOFRID and FORLI are shown for Frankfurt (Fig. 2) and Windhoek (Fig. 3). Based on the shape of the averaging kernels, lower (surface-480 hPa) and upper (480-225 hPa) tropospheric partial columns were defined. The upper limit of $225 \mathrm{hPa}$ was chosen to be within the boundary level of the aircraft profiles. The partial column averaging kernels for the lower and upper troposphere are given in black and were calculated according to Deeter (2002). At the two locations, we see differences between daytime and nighttime partial column averaging kernels: for nighttime measurements the vertical resolution (width of the averaging kernels) is lower and the maximum sensitivity is shifted upwards for the lower tropospheric averaging kernels. Especially at Frankfurt, FORLI daytime and nighttime averaging kernels show strong differences. The sensitivity near the surface is higher during the day. The lower and upper tropospheric nighttime averaging kernels are strongly overlapping, meaning that the lower and upper tropospheric information is correlated. For SOFRID 


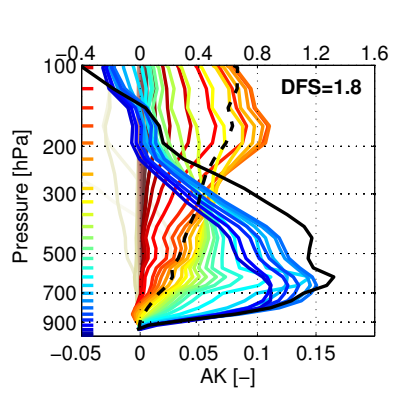

day

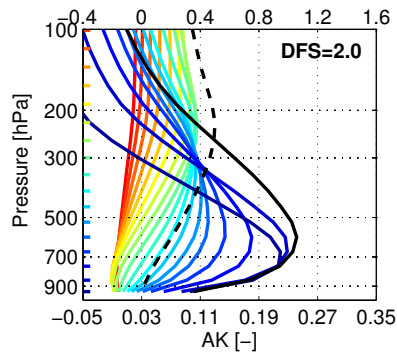

night
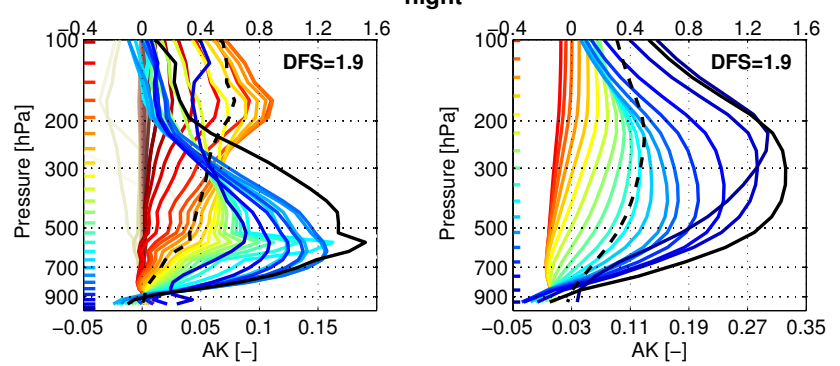

Fig. 2. SOFRID (left panel) and FORLI (right panel) averaging kernels (AK) (bottom $\mathrm{x}$-axis, colour lines) and normalised averaging kernels of partial columns (top $\mathrm{x}$-axis, black solid line: surface$480 \mathrm{hPa}$, black dashed line: $480-225 \mathrm{hPa}$ ), for a daytime (top panels) and nighttime (bottom panels) retrieval of a IASI pixel near Frankfurt $\left(50.1^{\circ} \mathrm{N}, 8.7^{\circ} \mathrm{E}\right)$ on 28 May 2008 . The nominal height of each averaging kernel is marked by the horizontal tick with corresponding colour.

the differences between daytime and nighttime averaging kernels are smaller. At both locations, the maximum sensitivity of the nighttime averaging kernels in the upper troposphere is shifted towards lower altitudes. The SOFRID lower tropospheric nighttime averaging kernel at Windhoek shows an irregularity in the upper troposphere.

\subsection{Global comparisons}

Global maps of lower (surface-480 hPa) and upper (480$225 \mathrm{hPa}$ ) tropospheric CO columns retrieved with SOFRID and FORLI are displayed in Fig. 4. Daily means are shown for 1 January and 1 July 2008, characterizing the winter and summer seasons.

In general the same features are captured by the two algorithms. The four top figures provide a boreal winter picture, with elevated $\mathrm{CO}$ values in the lower troposphere over West Africa, where biomass burning fires are active from October through January in the Sahel region. This CO-rich air is convectively lifted to the upper troposphere where it disperses over the African tropics towards the east coast of South America and the South Arabian peninsula (Edwards et al., 2003). In the lower troposphere, higher CO concentrations are found by FORLI compared to SOFRID for these regions affected by biomass burning. Over South-East Asia,
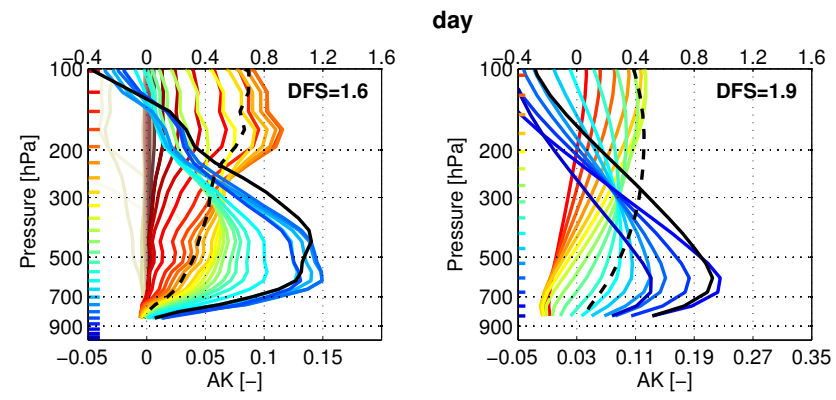

night
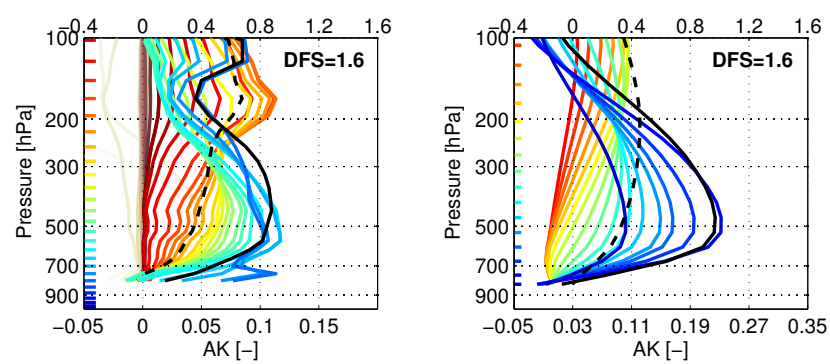

Fig. 3. As Fig. 2 for Windhoek $\left(22.6^{\circ} \mathrm{S}, 17.1^{\circ} \mathrm{E}\right)$ on 24 January 2008 . Windhoek lies at an altitude $\sim 1700 \mathrm{~m}$ hence the lower cut-off of the averaging kernels.

IASI detects highly polluted air-masses that are uplifted and advected along the North-East Asian coast. In these pollution cases higher CO columns are retrieved by FORLI than by SOFRID. In the upper troposphere, higher $\mathrm{CO}$ background values are observed by SOFRID at mid-latitudes.

In the bottom four figures, visualising the $\mathrm{CO}$ distributions on 1 July 2008, we see a shift of the biomass burning region from West Africa to Central Africa, featuring the beginning of the vegetation burning season, which lasts up to November. Both algorithms capture the displacement of a large plume of polluted air originating from North-East Asia which is rapidly transported over the Northern Pacific towards the Western Canadian coast. FORLI shows a band of elevated lower tropospheric CO values over Northern Europe and North Russia, which is not observed by SOFRID. Similar signatures are found on 1 January 2008. Again, higher upper tropospheric $\mathrm{CO}$ background values are observed by SOFRID at mid-latitudes.

In conclusion, SOFRID and FORLI show similar global distributions. FORLI retrieves higher $\mathrm{CO}$ concentrations in the lower troposphere for regions affected by biomass or fossil fuel burning, and lower $\mathrm{CO}$ background values in the midlatitudinal upper troposphere, compared to SOFRID.

\subsection{Correlations}

Table 1 presents the results of a linear regression analysis between the two IASI retrieval products and MOZAIC partial columns for 980 coincident observations taken at 30 airports 


\section{January 2008}
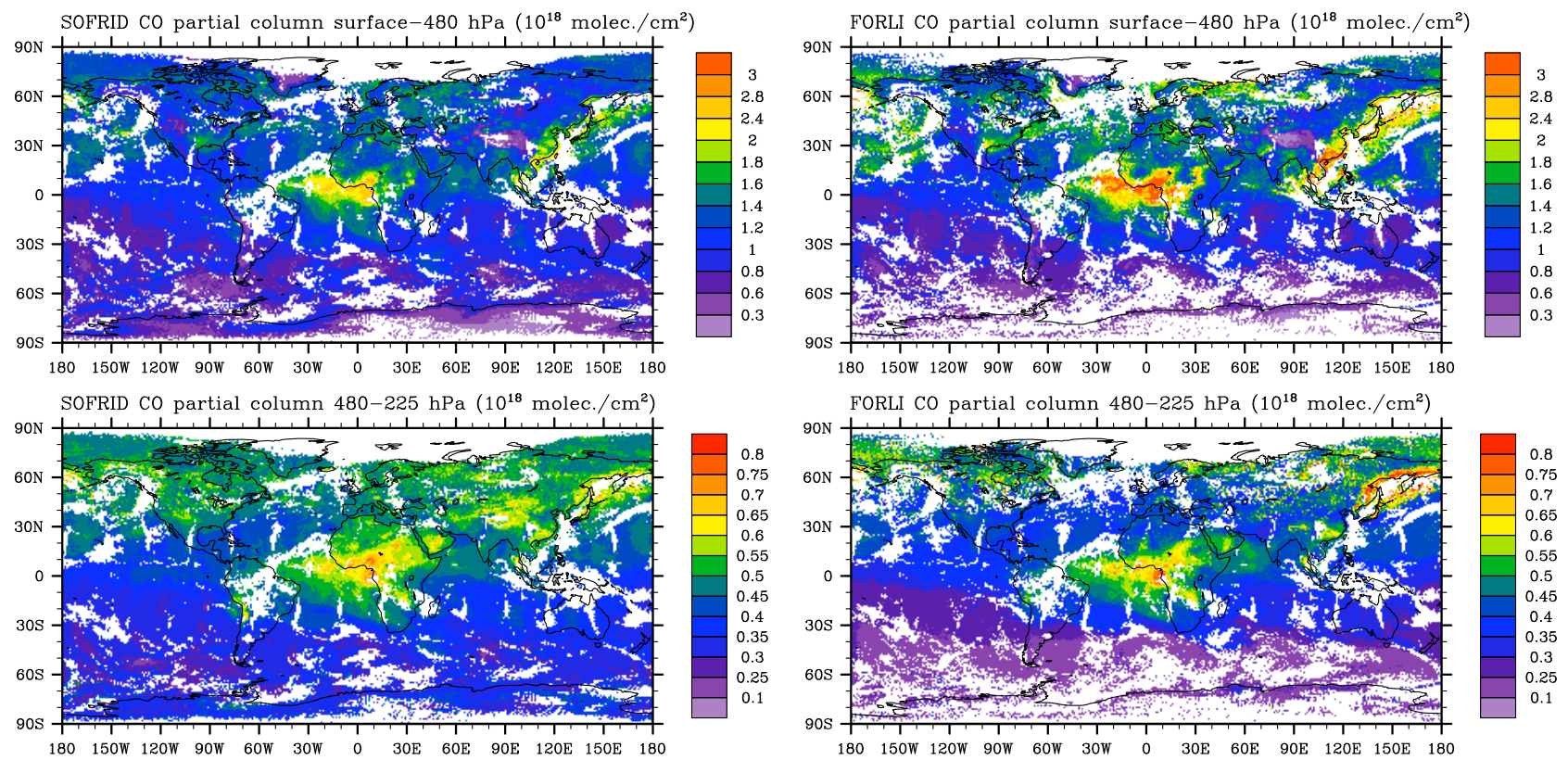

1 July 2008
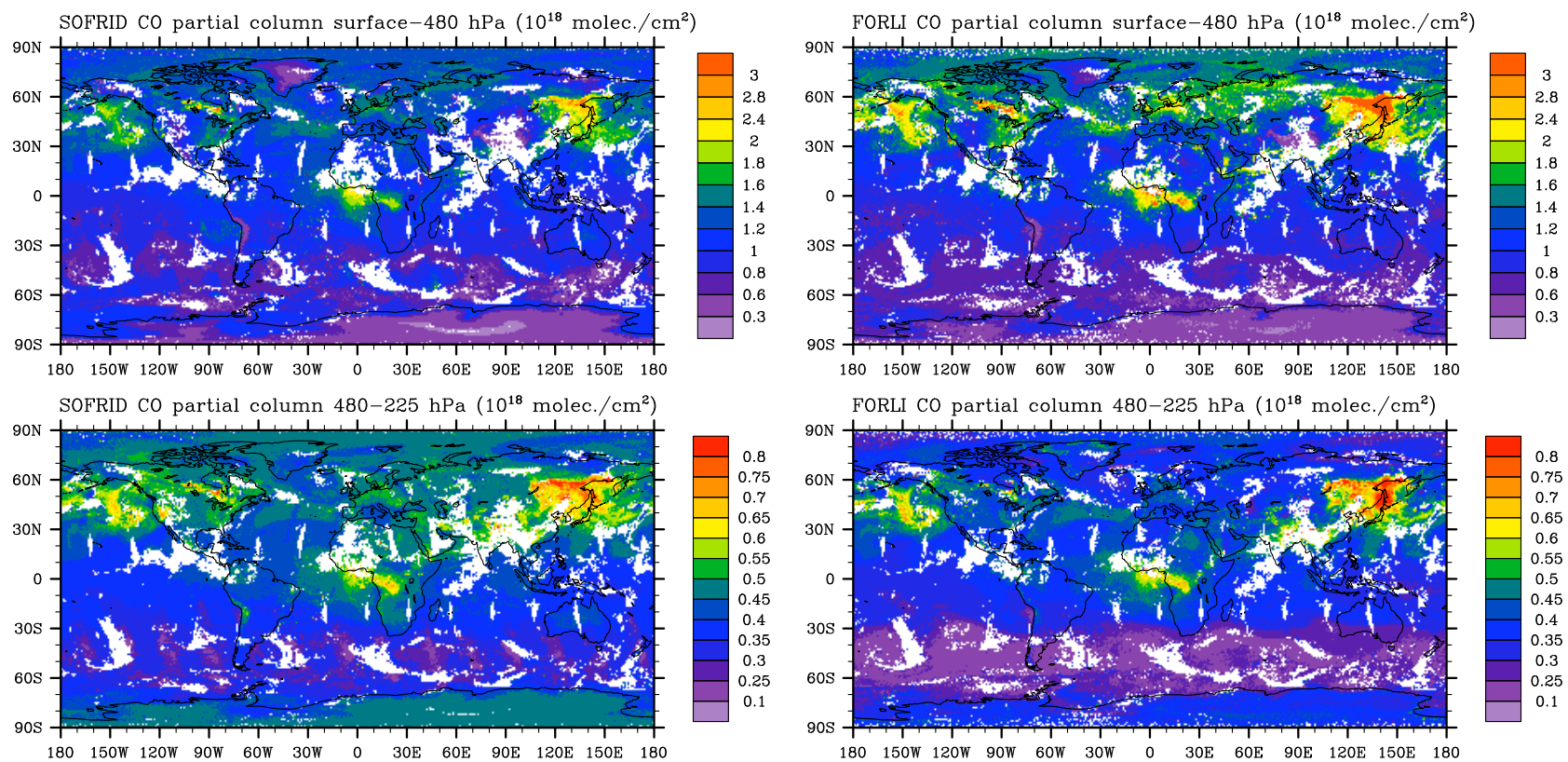

Fig. 4. Global plots of CO partial columns (surface- $480 \mathrm{hPa}$ and $480-225 \mathrm{hPa}$ ) retrieved with SOFRID (left panels) and FORLI (right panels) for 1 January 2008 (top panels) and 1 July 2008 (bottom panels), representing the global CO distribution during two composite seasons. Shown here are daily means (average of the daytime and nighttime observations). The pixels are binned on a $1^{\circ} \times 1^{\circ}$ grid.

in 2008 and 2009. The MOZAIC profiles were completed by coincident profiles from Aura/MLS at altitudes above the cruise altitude of the aircraft, to account for the missing altitudes where IASI is still sensitive. To account for the different resolution between the satellite and high-resolution in-situ data, a smoothing was applied to the MOZAIC profiles $\boldsymbol{x}_{\mathrm{MOZ}}$ by the IASI averaging kernels:

$$
\hat{\boldsymbol{x}}_{\mathrm{MOZ}}=\boldsymbol{x}_{\mathrm{a}}+\mathbf{A} \cdot\left(\boldsymbol{x}_{\mathrm{MOZ}}-\boldsymbol{x}_{\mathrm{a}}\right),
$$


Table 1. Slope $(a)$, intercept $(b)$ and correlation coefficients $(r)$ of the linear least squares fit of CO partial columns computed from MOZAIC profiles and IASI-retrieved profiles (SOFRID - top, FORLI - bottom). Results are given for lower (surface-480 hPa) and upper (480-225 hPa) tropospheric partial columns of raw (brackets) and smoothed MOZAIC compared to daytime and nighttime IASI retrievals.

\begin{tabular}{|c|c|c|c|c|c|c|c|}
\hline \multirow{4}{*}{ surface $-480 \mathrm{hPa}$} & \multirow{4}{*}{$\begin{array}{l}\text { day } \\
\text { night }\end{array}$} & \multicolumn{6}{|c|}{ SOFRID } \\
\hline & & \multicolumn{2}{|c|}{$a$} & \multicolumn{2}{|c|}{$b$} & \multicolumn{2}{|c|}{$r$} \\
\hline & & $(0.52)$ & 0.76 & $(0.52)$ & 0.32 & (0.69) & 0.85 \\
\hline & & $(0.42)$ & 0.57 & $(0.66)$ & 0.53 & $(0.70)$ & 0.80 \\
\hline \multirow[t]{4}{*}{$480-225 \mathrm{hPa}$} & day & $(0.37)$ & 0.51 & $(0.30)$ & 0.24 & $(0.58)$ & 0.70 \\
\hline & night & $(0.30)$ & 0.43 & $(0.35)$ & 0.29 & $(0.50)$ & 0.62 \\
\hline & & \multicolumn{6}{|c|}{ FORLI } \\
\hline & & \multicolumn{2}{|c|}{$a$} & \multicolumn{2}{|c|}{$b$} & \multicolumn{2}{|c|}{$r$} \\
\hline \multirow[t]{2}{*}{ surface$-480 \mathrm{hPa}$} & day & $(0.64)$ & 1.01 & $(0.47)$ & 0.09 & $(0.63)$ & 0.79 \\
\hline & night & $(0.54)$ & 0.84 & $(0.59)$ & 0.30 & $(0.65)$ & 0.74 \\
\hline \multirow[t]{2}{*}{$480-225 \mathrm{hPa}$} & day & $(0.30)$ & 0.57 & $(0.25)$ & 0.14 & $(0.42)$ & 0.71 \\
\hline & night & $(0.31)$ & 0.59 & $(0.27)$ & 0.17 & $(0.42)$ & 0.65 \\
\hline
\end{tabular}

Table 2. Statistics of the comparison between smoothed MOZAIC and IASI-retrieved partial columns (SOFRID - left, FORLI - right) at Frankfurt (top) and Windhoek (bottom). Results are given for lower (surface-480 hPa) and upper (480-225 hPa) tropospheric partial columns. The mean $(\mu)$ of the relative difference and the root-mean-square of the difference (rmsd) between smoothed MOZAIC and IASI partial columns, and the IASI $1-\sigma$ measurement $\left(S_{\text {meas }}\right)$ and retrieval error $\left(S_{\text {tot }}\right)$ are given.

\begin{tabular}{|c|c|c|c|c|c|c|c|c|}
\hline & \multicolumn{8}{|c|}{ Frankfurt } \\
\hline & \multicolumn{4}{|c|}{ SOFRID } & \multicolumn{4}{|c|}{ FORLI } \\
\hline & $\mu$ & rmsd & $S_{\text {meas }}$ & $S_{\text {tot }}$ & $\mu$ & rmsd & $S_{\text {meas }}$ & $S_{\text {tot }}$ \\
\hline surface $-480 \mathrm{hPa}$ & -3.8 & 14.2 & $6.6-12.6$ & $11.5-20.7$ & -13.0 & 22.4 & $4.2-8.0$ & $8.5-18.7$ \\
\hline \multirow[t]{4}{*}{$480-225 \mathrm{hPa}$} & -10.5 & 16.4 & $1.8-5.4$ & 7.3-9.7 & 0.9 & 15.8 & $2.7-4.5$ & $5.5-7.7$ \\
\hline & \multicolumn{8}{|c|}{ Windhoek } \\
\hline & \multicolumn{4}{|c|}{ SOFRID } & \multicolumn{4}{|c|}{ FORLI } \\
\hline & $\mu$ & rmsd & $S_{\text {meas }}$ & $S_{\text {tot }}$ & $\mu$ & rmsd & $S_{\text {meas }}$ & $S_{\text {tot }}$ \\
\hline surface $-480 \mathrm{hPa}$ & -12.8 & 19.1 & $8.6-15.6$ & $12.0-23.0$ & -1.6 & 14.2 & $5.9-10.5$ & $8.8-16.8$ \\
\hline $480-225 \mathrm{hPa}$ & -3.7 & 12.0 & $2.1-3.9$ & $5.3-7.7$ & 10.0 & 15.6 & $2.0-4.4$ & $5.7-8.1$ \\
\hline
\end{tabular}

where $\hat{\boldsymbol{x}}_{\mathrm{MOZ}}$ is the smoothed or convolved MOZAIC profile and $\boldsymbol{x}_{\mathrm{a}}$ and $\mathbf{A}$ are the a priori profile and averaging kernel matrix of the IASI retrieval (SOFRID or FORLI).

Table 1 gives the slope $(a)$, intercept $(b)$ and correlation coefficient $(r)$ of the comparison of IASI partial columns with smoothed MOZAIC partial columns. In brackets results of the comparison with partial columns calculated from the raw MOZAIC profiles are given. As expected, we see an improvement after smoothing of the in-situ data with the IASI averaging kernels. A high correlation is found in the lower troposphere (surface-480 hPa), with $r \sim 0.8$ for both retrievals. In the upper troposphere $(480-225 \mathrm{hPa})$ the correlation coefficients are $\sim 0.7$. For both algorithms, we see a slight improvement for daytime compared to nighttime retrievals. The slope and intercept are 1 and near 0 for daytime lower tropospheric FORLI and smoothed MOZAIC, and 0.76 and 0.32 for SOFRID.

The errors on the lower and upper tropospheric partial column have been estimated for SOFRID and FORLI (see Sect. 2.4). For SOFRID, the 1- $\sigma$ retrieval errors range between 10.7 and $20.5 \%$ for the lower troposphere and between 6.5 and $9.5 \%$ for the upper troposphere. FORLI retrieval errors are slightly lower and range between 7.7 and $19.1 \%$ and 5.3 and $8.3 \%$ for the lower and upper troposphere.

\subsection{Temporal variation}

Figures 5 and 6 present time series of lower and upper tropospheric columns at the airports of Frankfurt and Windhoek, respectively. The IASI data (red) are compared to the raw (gray) and smoothed MOZAIC (black) data at these 

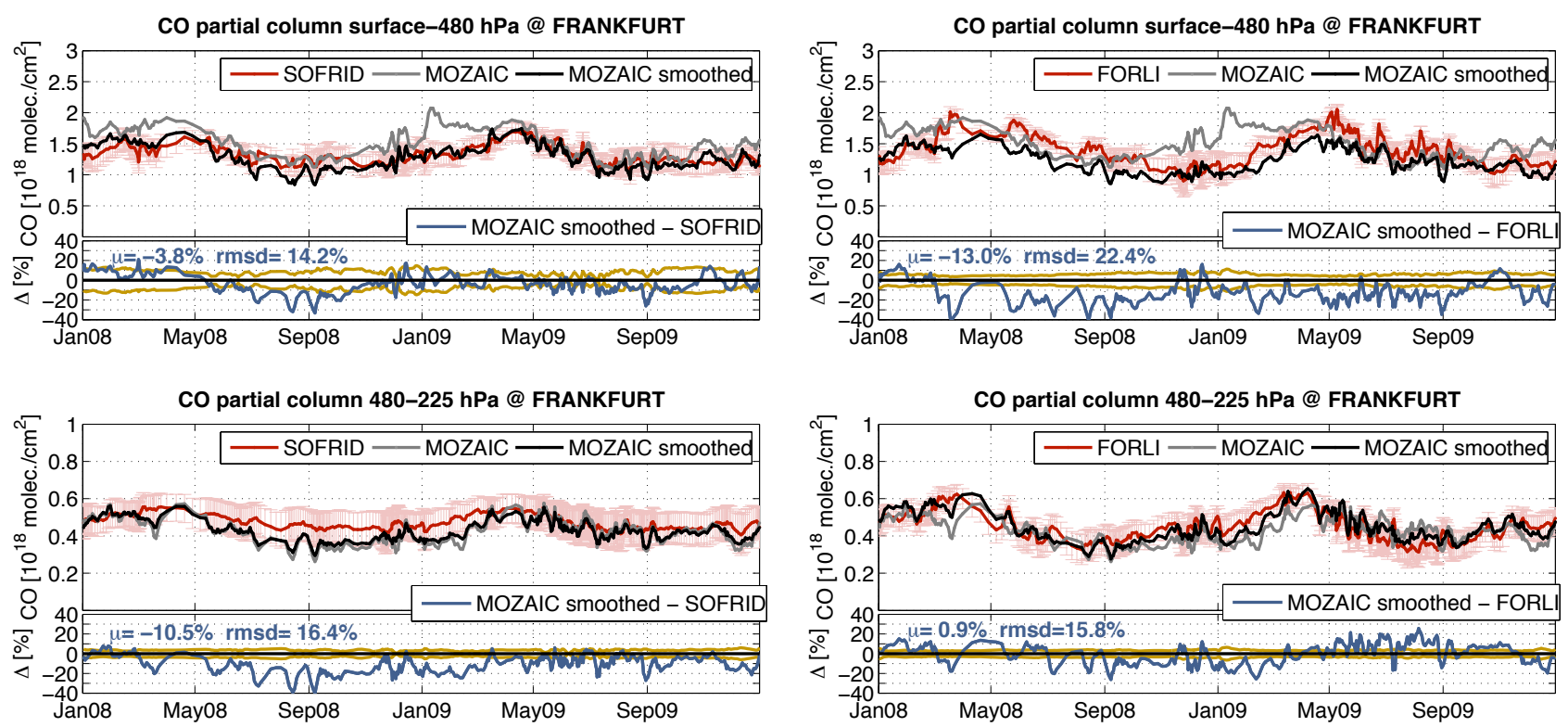

Fig. 5. Temporal variation of lower (surface-480 hPa) (top panels) and upper tropospheric (480-225 hPa) (bottom panels) partial columns at Frankfurt of MOZAIC versus SOFRID (left panels) and FORLI (right panels). IASI-retrieved partial columns are given in red, MOZAIC partial columns in grey and MOZAIC data smoothed with the averaging kernels of the respective IASI algorithm (SOFRID left, FORLI right) in black. The pink vertical bars represent the IASI partial column retrieval error. The relative difference between smoothed MOZAIC and IASI (MOZAIC-IASI/((MOZAIC + IASI)/2), in percentage) is given below each figure in blue, with its mean $(\mu)$ and root-mean-square (rmsd). The ochre contours represent the IASI measurement error. The data are smoothed by a 5-point moving average.
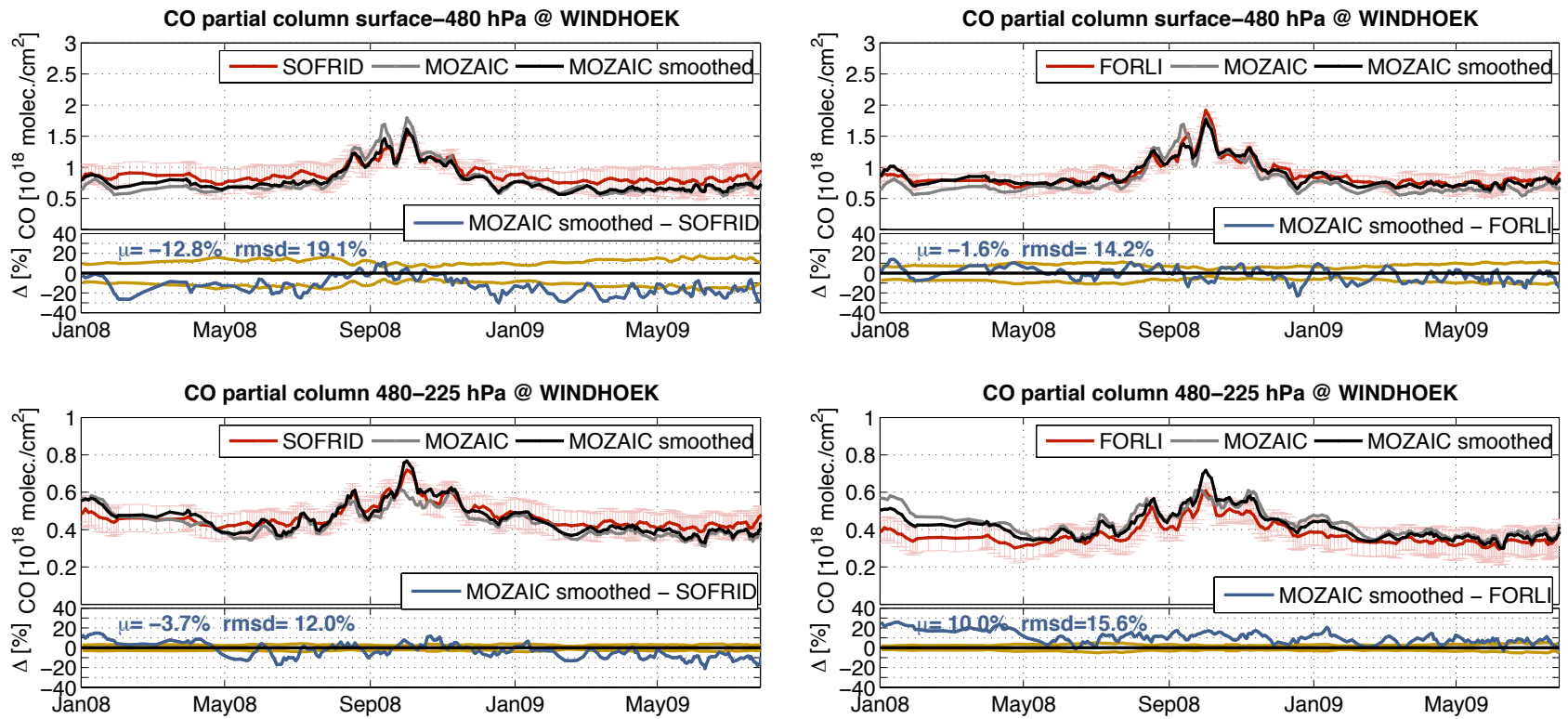

Fig. 6. As in Fig. 5 for Windhoek. Note the different timescale (MOZAIC flights to Windhoek stopped in July 2009).

two sites. The mean $(\mu)$ of the relative difference between smoothed MOZAIC and IASI partial columns (blue lines in Figs. 5 and 6) and the root-mean-square of the difference (rmsd) are summarized in Table 2. The IASI 1- $\sigma$ measurement $\left(S_{\text {meas }}\right)$ and retrieval error $\left(S_{\text {tot }}\right)$ are listed as well. The rmsd gives an estimate of the error of the (aircraft and retrieved) partial columns and should be compared to the calculated IASI error budget. Since the smoothed MOZAIC partial columns are compared, the smoothing error has not to be considered (Haefele, 2009), but only the measurement error and errors introduced by uncertainties in the fixed parameters of the radiative transfer model. Note that for SOFRID an 


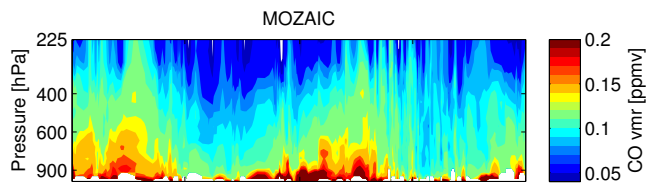

SOFRID daytime

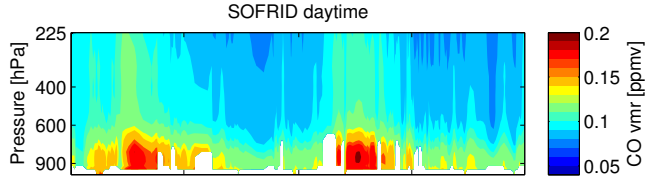

MOZAIC smoothed with SOFRID daytime AK
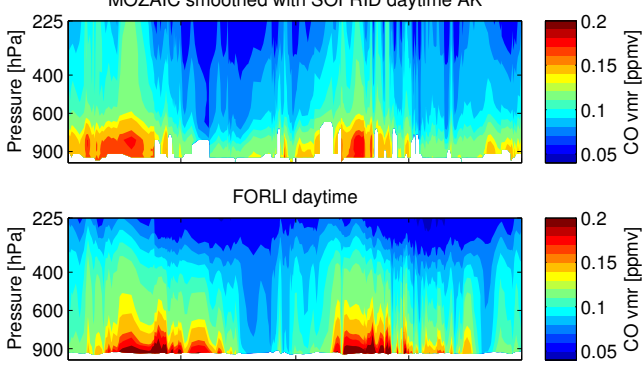

MOZAIC smoothed with FORLI daytime AK

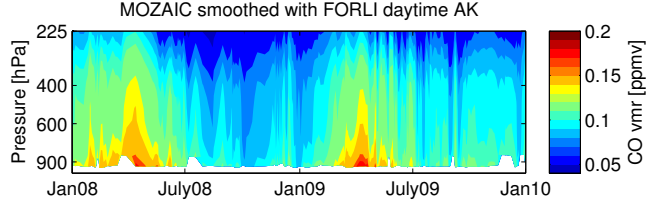

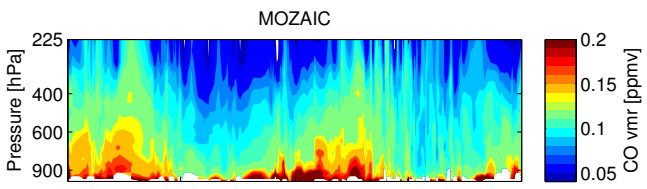

SOFRID nighttime
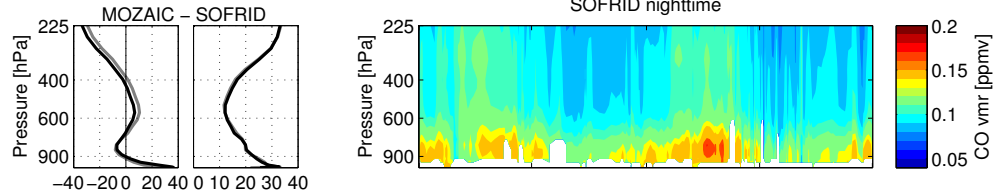

MOZAIC smoothed with SOFRID nighttime AK
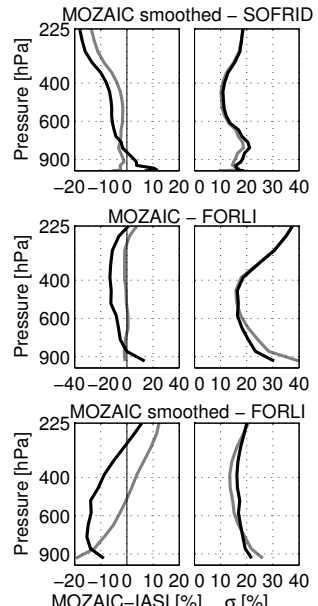
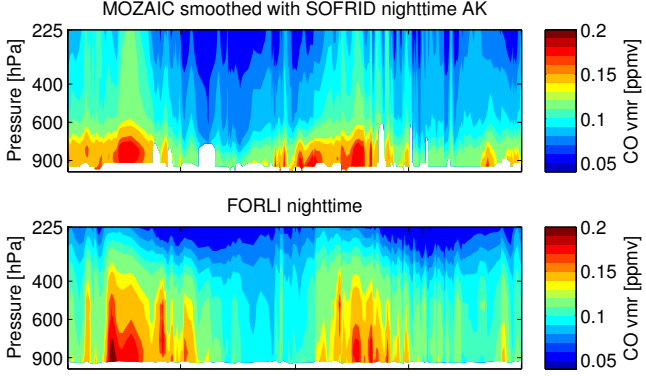

MOZAIC smoothed with FORLI nighttime AK

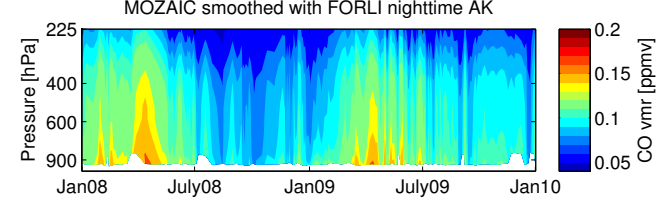

Fig. 7. Left panels: temporal variation of CO profiles at Frankfurt for the years 2008-2009, as observed by (from top to bottom panels) MOZAIC, daytime SOFRID, MOZAIC convolved with SOFRID daytime averaging kernels (AK), daytime FORLI and MOZAIC convolved with FORLI daytime AK. A 5-point moving average was applied. (middle) Normalised mean differences between MOZAIC and IASI profiles (MOZAIC-IASI/((MOZAIC + IASI)/2)) and standard deviation $(\sigma)$, for daytime (grey) and nighttime (black) retrievals, in percentage. Right panels: as the 5 panels on the left, but for IASI nighttime retrievals. Note that the time series of the raw MOZAIC profiles at Frankfurt is presented twice (the top left and right panels are identical).

augmented noise term for the retrieval was used, to include uncertainties in the forward model parameters. For FORLI, the radiometric noise used for the retrievals is close to the actual IASI radiometric noise leading to slightly lower measurement errors (see Sect. 2.4).

At Frankfurt (Fig. 5), both products capture the same seasonal variability as the aircraft observations, but underestimate the maxima in winter-spring in the lower troposphere. However, we see a great improvement after smoothing of the MOZAIC data, clearly visible for the 2009 winterspring period. This is linked to the insensitivity of IASI to boundary layer (BL) pollution in winter-spring when the BL height and the thermal contrasts are low (see the discussion below on Figs. 7 and 8). We find that SOFRID lower tropospheric $\mathrm{CO}$ is biased high compared to smoothed MOZAIC by $3.6 \%$. Note how SOFRID captures the same variability as MOZAIC on short timescales from January to September 2009. FORLI overestimates the lower tropospheric CO concentration relative to smoothed MOZAIC with a mean positive bias of $13.0 \%$. Furthermore, differences larger than $30 \%$ occur throughout the studied period. In the upper troposphere, FORLI and smoothed MOZAIC are in close agreement, with alternating slightly higher and lower $\mathrm{CO}$ concentrations, leading to a mean relative difference of $0.9 \%$. SOFRID underestimates the seasonal variability in the upper troposphere and shows overall a positive bias of $10.5 \%$ relative to MOZAIC. The rmsd between smoothed MOZAIC and IASI is larger for the FORLI product $(22.4 \%)$ compared to SOFRID $(14.2 \%)$ in the lower troposphere and is comparable in the upper troposphere $(\sim 16 \%$ ). These values are higher than the IASI measurement error estimated from the theoretical analyses, especially in the upper troposphere. This is not completely surprising as several error sources are not taken into account in the present study. First, one has to consider that the rmsd includes both the error on the MOZAIC and IASI partial columns. Second, even if the coincidence criteria are chosen optimally, the difference of sampling between the satellite and the aircraft is a source of random difference between both. Third, as previously explained, a rough estimate of the uncertainties introduced by the model parameters was made (or not considered for FORLI), which probably leads to an underestimation of these uncertainties. Finally, the use of a too low (respectively too high) radiometric noise (a priori variability) 

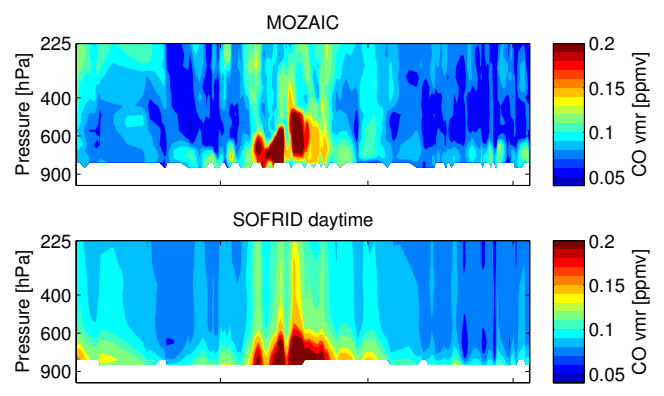

MOZAIC smoothed with SOFRID daytime AK
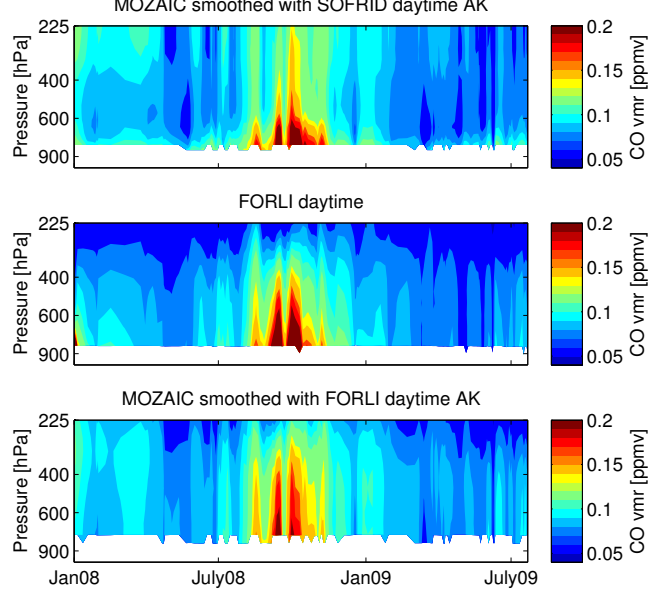
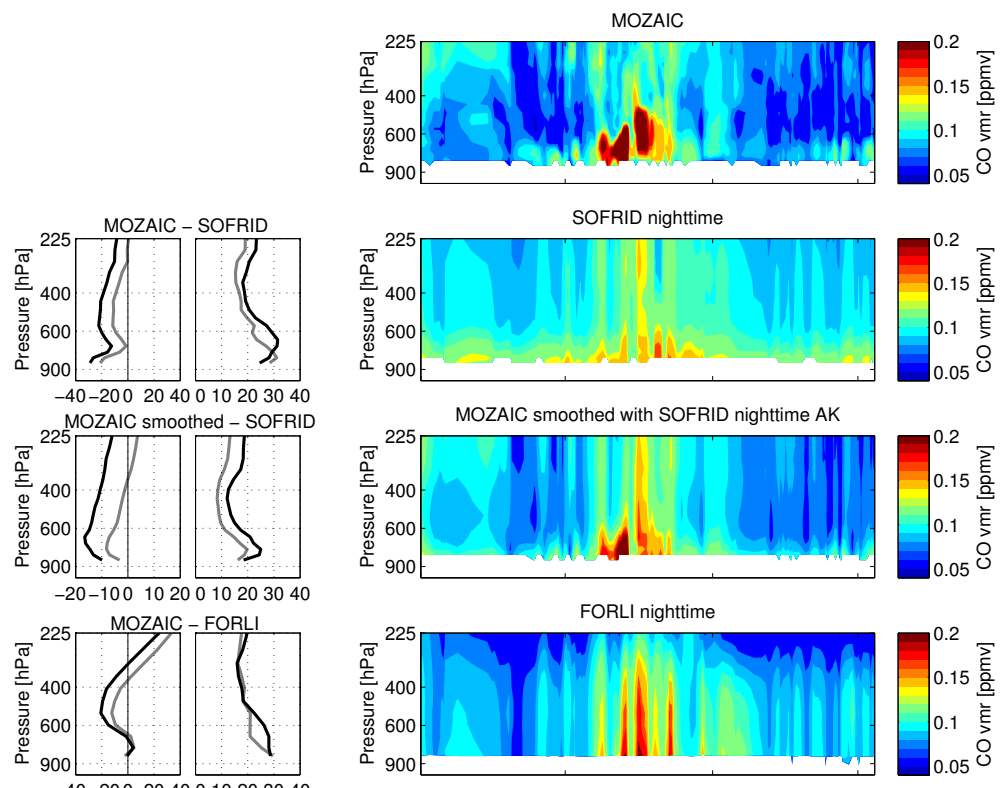

MOZAIC smoothed with FORLI nighttime AK

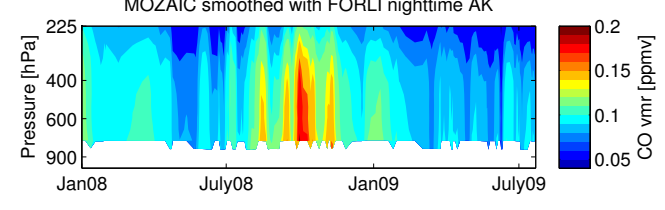

Fig. 8. As Fig. 7 for Windhoek from January 2008 to July 2009.

may result in an artificially high variability in the retrievals and therefore an excessive rmsd. Nevertheless, the cause of the discrepancies between error estimates and rmsd needs to be further investigated. Note that the measurement errors are roughly half of the retrieval errors (Table 2) showing that the smoothing error is by far the largest source of random error.

At Windhoek (Fig. 6), for both algorithms, we see a very good reproduction of the variability resulting from the vegetation fires in Southern Africa from August to November. In the lower troposphere, very close agreement is found between SOFRID and smoothed MOZAIC for the fire emission peaks, but we see an overestimation of the background $\mathrm{CO}$ values in December-July, leading to a mean relative difference of $-12.8 \%$. The larger overestimation of lower tropospheric $\mathrm{CO}$ at Windhoek than at Frankfurt can be explained by the low background concentrations at Windhoek throughout the year except during the short vegetation burning seasons. The fact that the MOZAIC data at Windhoek are not covering the period after August 2009 accentuates the low concentration bias in the data, because it implies a single vegetation burning season. Lower tropospheric FORLI has a small bias of $-1.6 \%$ relative to smoothed MOZAIC, although higher relative differences are observed for the fire maxima of $\sim 10 \%$. The analysis of the $\mathrm{CO}$ profiles presented later in this section will help to understand the lower tropospheric bias difference between Frankfurt and Windhoek for FORLI. In the upper troposphere, FORLI is biased low relative to both raw and smoothed MOZAIC, most pronounced in 2008, giving a mean relative difference of $10.2 \%$. Upper tropospheric SOFRID is biased high compared to smoothed MOZAIC by $3.7 \%$. Note the great improvement after smoothing for the third fire maxima in October 2008, where SOFRID overestimates the CO concentration compared to raw MOZAIC (the same holds for FORLI as well, if one would correct for the bias). In this case, a possible cause could be the contamination of upper tropospheric $\mathrm{CO}$ with lower tropospheric CO. As can be seen from Fig. 3, the averaging kernel of the upper tropospheric partial column (dashed black line) shows sensitivity to the lower troposphere. The extreme $\mathrm{CO}$ values found during the vegetation fire season, in combination with the high extension of the fire plumes (see discussion below), lead to this contamination effect. However, strong differences between the raw and smoothed MOZAIC data seem to be limited to this specific period. The rmsd is below 20 and $16 \%$ in the lower and upper troposphere respectively. The rmsd is greatly reduced for FORLI in the lower troposphere compared to the rmsd at Frankfurt. Again, rmsd values are higher than the measurement errors with larger discrepancies in the upper than in the lower troposphere.

In order to produce a complete picture of the performance of both retrievals, time series and mean differences of 
MOZAIC and IASI CO profiles at Frankfurt and Windhoek are displayed in Figs. 7 and 8. IASI daytime and nighttime comparisons with raw and smoothed MOZAIC profiles are shown. It is worth noting that Figs. 7 and 8 clearly highlight the different pollution conditions we have at the two airports: Frankfurt, a region affected by BL pollution (typically below $800 \mathrm{hPa}$ ), and Windhoek, a region affected by biomass fire plumes in Southern Africa, which are injected to higher altitudes (up to $\sim 500 \mathrm{hPa}$; Rio et al., 2010).

At Frankfurt (Fig. 7), we see a confirmation of the earlier assumption that the high $\mathrm{CO}$ concentrations observed by MOZAIC correspond to local CO emissions only affecting the BL. This pollution is not detected by the IASI instrument in winter when thermal contrast and the BL are low, leading to relative differences between raw MOZAIC and SOFRID profiles up to $40 \%$ at the surface. After smoothing we see a much better agreement in the lower troposphere, with relative differences between smoothed MOZAIC and daytime SOFRID profiles of less than $-3 \%$. SOFRID nighttime retrievals underestimate the BL pollution and slightly overestimate the $\mathrm{CO}$ background concentrations leading to differences with smoothed MOZAIC ranging from $+13 \%$ at the surface to $-7.5 \%$ at $400 \mathrm{hPa}$. In the upper troposphere, SOFRID shows a rather flat distribution with a positive bias, as previously seen in Fig. 6 .

FORLI retrieves well the BL pollution compared to raw MOZAIC, with the exception of the winter period due to the earlier explained limited sensitivity of IASI. Also, elevated $\mathrm{CO}$ values are retrieved by FORLI in July-August 2008 (most pronounced in the nighttime set), which are not observed in the raw MOZAIC data. The smoothed MOZAIC profiles demonstrate that the FORLI vertical resolution results in a diffusion of the raw MOZAIC BL CO concentrations to higher altitudes and leads to differences ranging from more than $-20 \%$ at the surface to $0 \%$ at $510 \mathrm{hPa}$ between smoothed MOZAIC and FORLI daytime profiles (around $-15 \%$ in the free troposphere for nighttime retrievals).

At Frankfurt, FORLI nighttime profiles are more smoothed over the lower troposphere than daytime retrievals. This difference results from the lower resolution for nighttime retrievals, as evidenced with Fig. 2 in Sect. 4.1.

At Windhoek, we can deduce from the raw MOZAIC profiles (Fig. 8 upper panels) that the $\mathrm{CO}$ emitted by the vegetation fires in Southern Africa mostly impacts the troposphere up to $400 \mathrm{hPa}$. During the fire periods, IASI-retrieved profiles and MOZAIC-smoothed profiles show high CO concentrations up to $225 \mathrm{hPa}$ indicating a contamination by the fire emissions above $400 \mathrm{hPa}$.

Nighttime SOFRID retrievals underestimate the high CO concentrations in the low and free troposphere during the vegetation fire period and overestimate the low $\mathrm{CO}$ background values, leading to the overall positive bias estimated by the relative differences. The same kind of behaviour was found at Frankfurt indicating a smoothing of the extreme $\mathrm{CO}$ values by SOFRID nighttime retrievals larger than indicated by the MOZAIC-smoothed data. The radiometric noise set conservatively to $1.41 \times 10^{-8} \mathrm{~W}\left(\mathrm{~cm}^{2} \mathrm{srcm}^{-1}\right)^{-1}$ may be too high resulting in a reduced retrieved variability. For FORLI, the bias profiles are similar at Windhoek and Frankfurt except that the large overestimation (up to 20\%) of FORLI in the lowermost layers at Frankfurt is not observed at Windhoek (Figs. 7 and 8). This may result from the fact that Windhoek is located at $\sim 1700 \mathrm{~m}$ a.s.l., above the altitude where the overestimation is the highest. Furthermore, most of the time (except during the vegetation burning season) the BL above Windhoek is less polluted than the BL above Frankfurt and FORLI has the tendency to overestimate the high rather than the low $\mathrm{CO}$ concentrations. These points highlighted by the profile analyses partly explain the difference in biases for FORLI lower tropospheric CO between Frankfurt and Windhoek.

The negative bias of $10 \%$, previously identified for FORLI in the upper troposphere (Fig. 6), is seen here by the underestimation of the CO concentrations above $480 \mathrm{hPa}$ compared to MOZAIC. This bias is more pronounced for the daytime compared to nighttime retrievals.

\section{Conclusions}

This study presented tropospheric CO profiles retrieved from IASI spectra by two different retrieval algorithms: SOFRID and FORLI. A quality assessment of the retrieved IASI CO products was given by a detailed comparison with airborne observations recorded observations recorded at 30 airports in 2008-2009 within the MOZAIC program. A correlation study of the coincidences between MOZAIC and the two IASI products of lower (surface-480 hPa) and upper (480$225 \mathrm{hPa}$ ) tropospheric partial columns showed correlation coefficients of $r \sim 0.8$ and $r \sim 0.7$ respectively. In the lower troposphere, FORLI reproduced the amplitude of the variations of smoothed MOZAIC data better than SOFRID (slopes closer to 1). The variability of the MOZAIC-smoothed data was slightly better captured by SOFRID, showing higher correlation coefficients. The retrieval error of the IASI products was estimated to be less than $21 \%$ and less than $10 \%$ for lower and upper tropospheric columns respectively, with slightly lower values for the FORLI retrieval.

The temporal variation of lower and upper tropospheric columns, as well as daytime and nighttime $\mathrm{CO}$ profiles, was investigated in detail at the two airports Frankfurt and Windhoek. During 2008-2009 these two airports are the only ones to have enough MOZAIC CO observations for a correct seasonal cycle sampling. Overall, both retrieval products showed close agreement with smoothed MOZAIC partial columns in terms of seasonal variability, especially in the lower troposphere. At Frankfurt, the pronounced smoothing of the MOZAIC profiles by the averaging kernels of SOFRID and FORLI in the winter-spring period indicated 
the insensitivity of IASI to BL pollution when the thermal contrast is low.

SOFRID lower tropospheric columns were positively biased by $3.8 \%$ at Frankfurt and $12.8 \%$ at Windhoek. Profile comparisons demonstrated an overestimation of the low $\mathrm{CO}$ background values and an underestimation of the high $\mathrm{CO}$ values by the nighttime SOFRID retrievals. This leads to a larger overestimation of lower tropospheric $\mathrm{CO}$ at Windhoek than at Frankfurt as Windhoek is characterized by low background concentrations with exception of the short vegetation burning season. In the upper troposphere, SOFRID was biased high by $10.5 \%$ at Frankfurt but showed a better agreement with smoothed MOZAIC at Windhoek (biased high by $3.7 \%)$.

FORLI lower tropospheric columns were positively biased $(13.0 \%)$ at Frankfurt. At Windhoek, a small positive bias of $1.6 \%$ relative to smoothed MOZAIC was found with increased relative difference values for the fire maxima $(\sim 10 \%)$. A closer investigation of the profiles revealed that, at Frankfurt, the polluted BL CO concentrations are smoothed to higher altitudes, most pronounced for the FORLI nighttime retrievals. In addition, an overestimation of the high $\mathrm{CO}$ concentrations at the lowermost altitudes by the daytime retrievals was observed. Windhoek is located at $\sim 1700 \mathrm{~m}$ a.s.l., above the altitude where FORLI overestimates $\mathrm{CO}$, and has a clean BL most of the time. This partly explains the lower bias observed in the lower troposphere at Windhoek than at Frankfurt. In the upper troposphere, FORLI was biased low by 0.9 and $10.0 \%$ at Frankfurt and Windhoek respectively.

Daytime and nighttime profiles at Windhoek of both SOFRID and FORLI indicated signatures of lower tropospheric contamination in the upper troposphere. However, we found no explanation for the differences in biases by the IASI data between Frankfurt and Windhoek in the upper troposphere.

The rmsd values between IASI retrievals and MOZAIC are larger than could be expected from the estimated errors, especially in the upper troposphere. Possible causes for this discrepancy include underestimation of errors from uncertainties in fixed parameters, sampling errors, and a too strong constraint applied on the measurement during the retrievals. One of the referees raised the concern that the measurement error (error due to noise and fixed parameters) likely has a bias component. This problem will be addressed in future developments of the retrieval algorithms, which are needed to better characterize and mitigate any quantified bias terms.

In conclusion, SOFRID and FORLI showed biases no higher than $13 \%$ compared to the MOZAIC reference set and showed their ability to correctly reproduce the $\mathrm{CO}$ variability in the lower and upper troposphere. Discrepancies found between the two IASI products and MOZAIC could in a large part be explained by the lower thermal contrast during nighttime, which leads to less vertically resolved nighttime measurements.
Acknowledgements. The IASI mission is a joint mission of EUMETSAT and the Centre National d'Etudes Spatiales (CNES, France). The IASI L1 data are distributed in near real time by EUMETSAT through the EUMETCast system distribution. This research was conducted as part of the IASI-chimie project, financed by the TOSCA/CNES program. We acknowledge the different partner institutions of the IAGOS Research Infrastructure, in addition to the European Commission, Airbus, and the airlines (Lufthansa, Austrian, Air France) for the transport free of charge of the instrumentation. The Authors would like to thank E. Borbas and R. Saunders for providing the RTTOV UW-IRemis module, in addition to the Ether French atmospheric database (CNESCNRS/INSU; http://ether.ipsl.jussieu.fr) for providing access to the IAGOS/MOZAIC data, IASI L1 data and temperature and water vapour profiles. P. F. Coheur, from the ULB group, is Research Associate (Chercheur Qualifié) with F.R.S.-FNRS. The research in Belgium was funded by the F.R.S.-FNRS, the Belgian State Federal Office for Scientific, Technical and Cultural Affairs, and the European Space Agency (ESA-Prodex arrangements). Financial support by the Actions de Recherche Concertées (Communauté Française de Belgique) is also acknowledged.

Edited by: A. J. M. Piters

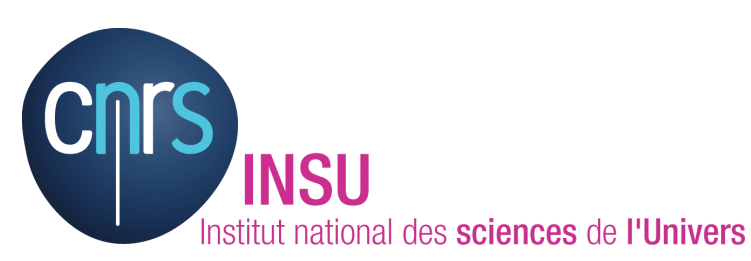

The publication of this article is financed by CNRS-INSU.

\section{References}

Barret, B., Turquety, S., Hurtmans, D., Clerbaux, C., Hadji-Lazaro, J., Bey, I., Auvray, M., and Coheur, P.-F.: Global carbon monoxide vertical distributions from spaceborne high-resolution FTIR nadir measurements, Atmos. Chem. Phys., 5, 2901-2914, doi:10.5194/acp-5-2901-2005, 2005.

Barret, B., Le Flochmoen, E., Sauvage, B., Pavelin, E., Matricardi, M., and Cammas, J. P.: The detection of post-monsoon tropospheric ozone variability over south Asia using IASI data, Atmos. Chem. Phys., 11, 9533-9548, doi:10.5194/acp-11-95332011, 2011.

Bergamaschi, P., Hein, R., Heimann, M., and Crutzen, P. J.: Inverse modeling of the global $\mathrm{CO}$ cycle 1 . Inversion of $\mathrm{CO}$ mixing ratios, J. Geophys. Res., 105, 1909-1927, 2000.

Borbas, E. E. and Ruston, B. C.: The RTTOV UWiremis IR land surface emissivity module, Associate Scientist mission report, Mission no. AS09-04, Document NWPSAF-MO-VS-042, Version 1.0, EUMETSAT Numerical Weather Prediction Satellite Applications Facility, Met Office, Exeter, UK, June 2010.

Brenninkmeijer, C. A. M. and Novelli, P. C.: Carbon monoxide, in: Encyclopedia Atmospheric Sciences, edited by: Holton, J. R., Academic Press, an imprint of Elsevier Science, London, 23892396, 2003. 
Chin, M., Jacob, D. J., Munger, J. W., Parrish, D. D., and Doddridge, B. G.: Relationship of ozone and carbon monoxide over North America, J. Geophys. Res., 99, 565-573, 1994.

Clerbaux, C., Coheur, P.-F., Hurtmans, D., Barret, B., Carleer, M., Colin, R., Semeniuk, K., McConnell, J. C., Boone, C., and Bernath, P.: Carbon monoxide distribution from the ACEFTS solar occultation measurements, Geophys. Res. Lett., 32, L16S01, doi:10.1029/2005GL022394, 2005.

Clerbaux, C., Boynard, A., Clarisse, L., George, M., Hadji-Lazaro, J., Herbin, H., Hurtmans, D., Pommier, M., Razavi, A., Turquety, S., Wespes, C., and Coheur, P.-F.: Monitoring of atmospheric composition using the thermal infrared IASI/MetOp sounder, Atmos. Chem. Phys., 9, 6041-6054, doi:10.5194/acp-9-6041-2009, 2009.

Clough, S. A., Shephard, M. W., Mlawer, E. J., Delamere, J. S., Iacono, M. J., Cady-Pereira, K., Boukabara, S., and Brown, P. D.: Atmospheric radiative transfer modeling: a summary of the AER codes, J. Quant. Spectrosc. Ra., 91, 233-244, 2005.

Deeter, M.: Calculation and application of MOPITT averaging kernels, available at: http://www.acd.ucar.edu/mopitt/ data-interpretation.shtml, last access: 24 July 2002.

Dufour, G., Eremenko, M., Griesfeller, A., Barret, B., LeFlochmoën, E., Clerbaux, C., Hadji-Lazaro, J., Coheur, P.-F., and Hurtmans, D.: Validation of three different scientific ozone products retrieved from IASI spectra using ozonesondes, Atmos. Meas. Tech., 5, 611-630, doi:10.5194/amt-5-611-2012, 2012.

Edwards, D. P., Lamarque, J.-F., Attié, J.-L., Emmons, L. K., Richter, A., Cammas, J.-P., Gille, J. C., Francis, G. L., Deeter, M. N., Warner, J., Ziskin, D. C., Lyjak, L. V., Drummond, J. R., and Burrows, J. P.: Tropospheric ozone over the Tropical Atlantic: a satellite perspective, J. Geophys. Res., 108, 4237, doi:10.1029/2002JD002927, 2003.

Forster, C., Wandinger, W., Wotawa, G., James, P., Mattis, I., Althausen, D., Simmonds, P., O’Doherty, S., Jennings, S. G., Kleefeld, C., Schneider, J., Trickl, T., Kreipl, S., Jäger, H., and Stohl, A.: Transport of boreal forest fire emissions from Canada to Europe, J. Geophys. Res., 106, 887-906, 2001.

George, M., Clerbaux, C., Hurtmans, D., Turquety, S., Coheur, P.F., Pommier, M., Hadji-Lazaro, J., Edwards, D. P., Worden, H., Luo, M., Rinsland, C., and McMillan, W.: Carbon monoxide distributions from the IASI/METOP mission: evaluation with other space-borne remote sensors, Atmos. Chem. Phys., 9, 8317-8330, doi:10.5194/acp-9-8317-2009, 2009.

Haefele, A.: Measurements of Tropospheric, Stratospheric and Mesospheric Water Vapor by Ground Based Microwave Spectro-Radiometry, Doctoral Thesis, http://www.iapmw.unibe. ch/publications/pub-detail.php?lang=en\&id=3330, last access: August 2012, Institute for Applied Physics, University of Bern, Bern, 2009.

Hauglustaine, D. A., Hourdin, F., Jourdain, L., Filiberti, M.A., Walters, S., Lamarque, J.-F., and Holland, E. A.: Interactive chemistry in the Laboratoire de Météorologie Dynamique general circulation model: description and background tropospheric chemistry, J. Geophys. Res., 109, D04314, doi:10.1029/2003JD003957, 2004.
Hurtmans, D., Coheur, P. F., Wespes, C., Clarisse, L., Scharf, O., Clerbaux, C., Hadji-Lazaro, J., George, M., and Turquety, S.: FORLI radiative transfer and retrieval code for IASI, J. Quant. Spectrosc. Ra., 113, 1391-1408, doi:10.1016/j.jqsrt.2012.02.036, 2012.

Illingworth, S. M., Remedios, J. J., Boesch, H., Moore, D. P., Sembhi, H., Dudhia, A., and Walker, J. C.: ULIRS, an optimal estimation retrieval scheme for carbon monoxide using IASI spectral radiances: sensitivity analysis, error budget and simulations, Atmos. Meas. Tech., 4, 269-288, doi:10.5194/amt-4-269-2011, 2011.

Logan, J., Prather, M. J., Wofsy, S. C., and McElroy, M. B.: Tropospheric chemistry: a global perspective, J. Geophys. Res., 86, 7210-7254, 1981.

Marenco, A., Thouret, V., Nédélec, P., Smit, H., Helten, M., Kley, D., Karcher, F., Simon, P., Law, K., Pyle, J., Poschmann, G., Von Wrede, R., Hume, C., and Cook, T.: Measurement of ozone and water vapour by Airbus in-service aircraft: the MOZAIC airborne program, An overview, J. Geophys. Res., 103, 25631-25642, 1998.

Matricardi, M.: Technical Note: An assessment of the accuracy of the RTTOV fast radiative transfer model using IASI data, Atmos. Chem. Phys., 9, 6899-6913, doi:10.5194/acp-9-6899-2009, 2009.

Matricardi, M., Chevallier, F., Kelly, G., and Thepaut, J. N.: An improved general fast radiative transfer model for the assimilation of radiance observations, Q. J. Roy. Meteorol. Soc., 130, 153173, 2004.

Nedelec, P., Cammas, J.-P., Thouret, V., Athier, G., Cousin, J.-M., Legrand, C., Abonnel, C., Lecoeur, F., Cayez, G., and Marizy, C.: An improved infrared carbon monoxide analyser for routine measurements aboard commercial Airbus aircraft: technical validation and first scientific results of the MOZAIC III programme, Atmos. Chem. Phys., 3, 1551-1564, doi:10.5194/acp-3-15512003, 2003.

O’Dell, C. W., Connor, B., Bösch, H., O’Brien, D., Frankenberg, C., Castano, R., Christi, M., Eldering, D., Fisher, B., Gunson, M., McDuffie, J., Miller, C. E., Natraj, V., Oyafuso, F., Polonsky, I., Smyth, M., Taylor, T., Toon, G. C., Wennberg, P. O., and Wunch, D.: The ACOS $\mathrm{CO}_{2}$ retrieval algorithm - Part 1: Description and validation against synthetic observations, Atmos. Meas. Tech., 5, 99-121, doi:10.5194/amt-5-99-2012, 2012.

Parrish, D. D., Holloway, J. S., Trainer, M., Murphy, P. C., Forbes, G. L., and Fehsenfeld, F. C.: Export of North American ozone pollution to the North Atlantic Ocean, Science, 259, 1436-1439, 1993.

Pavelin, E. G., English, S. J., and Eyre, J. R.: The assimilation of cloud-affected infrared satellite radiances for numerical weather prediction, Q. J. Roy. Meteorol. Soc., 134, 737-749, 2008.

Pommier, M., Law, K. S., Clerbaux, C., Turquety, S., Hurtmans, D., Hadji-Lazaro, J., Coheur, P.-F., Schlager, H., Ancellet, G., Paris, J.-D., Nédélec, P., Diskin, G. S., Podolske, J. R., Holloway, J. S., and Bernath, P.: IASI carbon monoxide validation over the Arctic during POLARCAT spring and summer campaigns, Atmos. Chem. Phys., 10, 10655-10678, doi:10.5194/acp-1010655-2010, 2010. 
Rio, C., Hourdin, F., and Chédin, A.: Numerical simulation of tropospheric injection of biomass burning products by pyro-thermal plumes, Atmos. Chem. Phys., 10, 3463-3478, doi:10.5194/acp10-3463-2010, 2010.

Rodgers, C. D.: Inverse Methods for Atmospheric Sounding: Theory and Practice, World Scientific Publishing Co. Pte. Ltd., Singapore, 2000.

Rothman, L. S., Jacquemart, D., Barbe, A., Benner, D. C., Birk, M., Brown, L. R., Carleer, M. R., Chackerian Jr., C., Chance, K., Coudert, L. H., Dana, V., Devi, V. M., Flaud, J.-M., Gamache, R. R., Goldman, A., Hartmann, J.-M., Jucks, K. W., Maki, A. G., Mandin, J.-Y., Massie, S. T., Orphal, J., Perrin, A., Rinsland, C. P., Smith, M. A. H., Tennyson, J., Tolchenov, R. N., Toth, R. A., Vander Auwera, J., Varanasi, P., and Wagner, G.: The HITRAN 2004 molecular spectroscopic database, J. Quant. Spectrosc. Ra., 96, 139-204, 2005.

Saunders, R., Matricardi, M., and Brunel, P.: An improved fast radiative transfer model for assimilation of satellite radiance observations, Q. J. Roy. Meteorol. Soc., 125, 1407-1425, 1999.

Schlüssel, P., Hultberg, T. H., Phillips, P. L., August, T., and Calbet, X.: The operational IASI Level 2 processor, Adv. Space Res., 36, 982-988, doi:10.1016/j.asr.2005.03.008, 2005.

Shindell, D. T., Faluvegi, G., Koch, D. M., Schmidt, G. A., Unger, N., and Bauer, S. E.: Improved Attribution of Climate Forcing to Emissions, Science, 326, 716-718, doi:10.1126/science.1174760, 2009.
Turquety, S., Hurtmans, D., Hadji-Lazaro, J., Coheur, P.-F., Clerbaux, C., Josset, D., and Tsamalis, C.: Tracking the emission and transport of pollution from wildfires using the IASI CO retrievals: analysis of the summer 2007 Greek fires, Atmos. Chem. Phys., 9, 4897-4913, doi:10.5194/acp-9-4897-2009, 2009.

Volz-Thomas, A., Berg, M., Heil, T., Houben, N., Lerner, A., Petrick, W., Raak, D., and Pätz, H.-W.: Measurements of total odd nitrogen $\left(\mathrm{NO}_{\mathrm{y}}\right)$ aboard MOZAIC in-service aircraft: instrument design, operation and performance, Atmos. Chem. Phys., 5, 583595, doi:10.5194/acp-5-583-2005, 2005.

Voulgarakis, A., Telford, P. J., Aghedo, A. M., Braesicke, P., Faluvegi, G., Abraham, N. L., Bowman, K. W., Pyle, J. A., and Shindell, D. T.: Global multi-year $\mathrm{O}_{3}-\mathrm{CO}$ correlation patterns from models and TES satellite observations, Atmos. Chem. Phys., 11, 5819-5838, doi:10.5194/acp-11-5819-2011, 2011.

Wan, Z.: New refinements and validation of the MODIS LandSurface Temperature/Emissivity products, Remote Sens. Environ., 112, 59-74, doi:10.1016/j.rse.2006.06.026, 2008.

Worden, J., Kulawik, S. S., Shephard, M. W., Clough, S. A., Worden, H., Bowman, K., and Goldman, A.: Predicted errors of tropospheric emission spectrometer nadir retrievals from spectral window selection, J. Geophys. Res., 109, D09308, doi:10.1029/2004JD004522, 2004.

Zhou, D. K., Larar, A. M., Liu, X., Smith, W. L., Strow, L. L., and Yang, P.: Global land surface emissivity retrieved from satellite ultraspectral IR measurements, IEEE T. Geosci. Remote, 49, 1277-1290, doi:10.1109/TGRS.2010.2051036, 2011. 